\title{
The Effect of Education for Future Program on Teachers' Competencies in a Public School
}

\author{
Kifaya Sabbah, Saddam Kobari, May Ali Ahmad, Wajeeh Daher* \\ Faculty of Educational Sciences, An-Najah National University, Nablus, Palestine
}

Received March 19, 2020; Revised April 28, 2020; Accepted May 20, 2020

Copyright $(02020$ by authors, all rights reserved. Authors agree that this article remains permanently open access under the terms of the Creative Commons Attribution License 4.0 International License

\begin{abstract}
The current study aimed to explore the effect of the Education for Future program on the practices of female teachers in a public school. The study participants were six female teachers form an elementary school. Besides, the study aimed to answer two main research questions. First, what is the effect of the education for future program on the educational practices of female teachers in public schools? Second, what are the challenges that face the female teachers who were involved in the program? Data collection was done through interviews with the participants, as well as class observations. Data analysis used the thematic coding to analyze data. The results of the research revealed that the program developed teachers' competencies since it improved their teaching styles, teaching methods and strategies, as well as their assessment strategies. Furthermore, it developed the teachers' classroom management, their technology integration in the classes, the students' interaction, and the students' values and attitudes. Besides, the results showed that the teachers faced challenges while implementing the project, such as how to introduce the new strategies and methods to their students, and how to use technology effectively. However, the results showed that the teachers could overcome those challenges by cooperation and asking for help and support.
\end{abstract}

Keywords Educating Program, Teachers' Competencies, Public School, Professional Development

\section{Introduction}

Education plays a powerful role in any society, where it is considered as an indispensable instrument for bringing positive change in the social, political, economic and cultural life of people. Educational processes are shaped by many important agents, and the teacher is one of them. The teacher is claimed to play a central role in education. Consequently, preparing teachers for the teaching profession is conceived as being a higher priority in any country since this profession is considered as being challenging and critical. Hence, successful teaching may lead to nations' rising and progress in different domains [1]. In order to establish a productive relationship with students, teachers need to have some qualities such as a high level of awareness, classroom management skills and an ability to make the learning environment qualified [2]. Besides, teachers should have knowledge of children's learning styles, how they address different individuals, how they evaluate teaching and how to manage a class [3].

Indeed, teachers can play an active role in their own professional development. Hence, it is the responsibility of schools and administrators to provide opportunities for teacher training and professional education [4]. One such opportunity is the educating program. The present research describes the impact of an education program on teachers' competencies. This program, which is called Education for Future (E4F), was implemented by the Palestinian ministry of education, represented by the national institute for educational training. The program was fundraised by USAID. One hundred schools were targeted; the sample of the program contained 500 teachers who teach Arabic language, English language, mathematics, science and technology. The program aimed at improving teaching competencies for teachers who teach $5^{\text {th }}$ to $10^{\text {th }}$ grades. The present research reports the effects of the implementation of this program on teachers' competencies in one public school during one scholastic year, from 18/9/2018-5/5/2019. The number of training hours was $360.30 \%$ of those hours were theoretical, and $70 \%$ of those hours were practical. 


\section{Literature Review}

Professional development programs play a major role in improving teachers' competencies [5]. Besides, Desimone [6] indicated that effective professional development updates teachers content knowledge, exposes them to new teaching strategies, sustains their teaching effectiveness, and promotes continuous growth. In addition, professional development can improve teaching quality. To ensure effective teaching in every classroom, educators must have opportunities to refine and expand their practice, reflect on how their practice impacts student learning, and engage in ongoing improvement to address learning challenges in the school [5]. Furthermore, Desimone [6] added that recent professional development programs focus on content, active learning, coherence, duration, and collective participation. Very recent studies are already including this set of core features as critical components of effective professional development.

Moreover, Wei, et al. [5] stated that the following factors develop the quality in services program development. First, the use of an ongoing process instead of one-shot workshop. Second, emphasizing collaborative participation rather than isolation. Third, tailoring training to meet the specific needs of teachers as opposed to such general goals as improving teaching and learning. Fourth, providing hands-on opportunities to construct new knowledge instead of lectures. Finally, connecting workshop developed knowledge to classroom practice through coaching.

\subsection{Teaching Competencies}

Competencies defined as the requirements of a "competency-based" teacher education and include the knowledge, skills and values a teacher-trainee must demonstrate for successful completion of a teacher education programme [7]. For instance, Nessipbayeva [7] stated that the competency has the following characteristics. First, a competency consists of one or more skills whose mastery would enable the attainment of the competency. Second, a competency is linked to all three of the domains under which performance can be assessed: knowledge, skills and attitude. Third, possessing a performance dimension, competencies are observable and demonstrable. Finally, since competencies are observable, they are also measurable.

Also, Shmelev [8] found that a competency is more than just knowledge and skills; it involves the ability to meet complex demands by drawing on and mobilizing psychosocial resources (including skills and attitudes) in a specific context. Competency is essential to an educator's pursuit of excellence. Teachers need a wide range of competencies in order to face the complex challenges of today's world. Teaching competency is an inherent element of an effective training process, one that aspires to contribute to the welfare of one country or the world, itself. The teaching skills and life-long learning competencies of professional teachers comprise the following. First, to perform complex pedagogical duties. Second, to be well-spoken, in good mental and physical health, stable and tolerant. Third, to have a propensity to work with the younger generation, good communicative and observational skills, tact, a vivid imagination, and leadership.

In addition, Nessipbayeva [7] stated that educators should demonstrate the following competencies. First of all, effective classroom management, maximizing efficiency, maintaining discipline and morale, promoting teamwork, planning, communicating, focusing on results, evaluating progress, and making constant adjustments. A range of strategies should be employed to promote positive relationships, cooperation, and purposeful learning. Organizing, assigning, and managing time, space and activities should ensure the active and equitable engagement of students in productive tasks. Moreover, effective teaching practices, representing differing viewpoints, theories, "ways of knowing" and methods of inquiry in the teaching of subject matter concepts. Multiple teaching and learning strategies should help engage students in active learning opportunities that promote the development of critical thinking, problem solving, and performance capabilities while helping them assume responsibility for identifying and using learning resources. In addition, effective assessment, incorporating formal tests; responses to quizzes; evaluation of classroom assignments, student performances and projects, and standardized achievement tests to understand what students have learned. Assessment strategies should be developed that involve learners in self-assessment activities to help them become aware of their strengths and needs and encourage them to set personal goals for learning. Furthermore, technology skills, knowing when and how to use current educational technology, as well as the most appropriate type and level of technology to maximize student learning.

Augskalne and Garjane [9] conducted a study about formation of teachers' competences in further education; research method was content analysis of 210 questionnaires filled in by vocational education teachers after attending a training course and content analysis of their self-assessment. The results showed that teacher's competences are only partially formed and incomplete. The results showed that the content of the course "Fundamental pedagogical work" allows for the obtaining of initial pedagogical competences, however, the shaping of participants' meta-competences needs to be activated.

Moreover, Pesti [10] conducted a study to reveal the role of practicum in ITE programmes in developing student teachers' competences and preparing them for conducting practice-oriented research in the cases of two universities from Hungary and Austria. Data was collected 
through document analysis (course descriptions, $n=63$ ), and interviews (student teachers, $\mathrm{n}=6$ ) and group interviews (with the total involvement of 61 student teachers, $n=8$ ). The present study revealed that the research-related methodological repertoire of student teachers is mostly restricted to lesson observations, interviews, and questionnaires, and there is a lack of research into their practice.

Besides, Peressini et al. [11] offered a conceptual framework that infers complex reflexive relationships between teaching practices and teachers' developing knowledge and beliefs about math, math-specific pedagogy, and professional identity. This model includes the knowledge, practice, student learning components, and an emphasis on subject specific content, and is consistent with the notion of interactive paths. Furthermore, Field [12] concluded that the establishment of competency-based teacher education schemes has challenged traditional thinking about teacher education, while the idea of demonstrable competencies has contemporary appeal in terms of accountability.

\section{Research Questions}

The current research aims to answer the following research questions:

1. What is the effect of the E4F program on the educational practices of teachers in a public school?

2. What are the challenges that face the teachers who were involved in the program?

\section{Methodology}

\subsection{Research Context and Participants}

The training was experience-based learning in which participants were trained theoretically and practically. The participants had to practice what they have learned by implementing specific tasks. Then, the participants took two courses for 6 hours to discuss tasks, reflect on the previous activities, experience what they acquired while participating, and communicate online with the other participants, with the facilitator and the program management via Moodle. The participants have passed the graduation project to get a diploma certificate in professional education.
To conduct this research, we chose a purposive sample from a public school in Palestine. To conduct the interviews and class observations, we chose six teachers who teach different subjects. The participants were two mathematics teachers, one biology and chemistry teacher, one Arabic language teacher, one English language teacher and one technology teacher.

\subsection{The Educating Program:}

The program was implemented by the Palestinian ministry of education represented by the national institute for educational training. It was fundraised by the USAID. The program included the professional diploma which was specialized in leadership, training teachers and supervisors. The program targeted 100 school with 100 principal, 500 teachers who taught English language, Arabic language, mathematics, science and technology, and 90 educational supervisors.

The program aimed at developing the competencies of teachers who teach 5th -10 th grades, principals and educational supervisors in order to develop their professional development. The program lasted for a year, and it was based on experience- based learning, in which the participant encounters many stages during training, which are: one face to face meeting every month, one day for a training complex that associated either with the criteria of the school or the educational competencies of the teacher, or the competencies of the supervisor for supervisors. The trainee is asked to do practical tasks after being involved in two learning seminars, with 3 hours for each seminar, in order to discuss tasks and reflect on the activities related to the given tasks. In addition, the program facilitated the process of online learning among the participants, the facilitator and program management via Moodle, which contained many supporting activities and tasks related to the face to face meeting. The program ended with a graduation project for every participant. The teachers, principals and supervisors, who participated in the program and passed the requirements of the trainings, received an authorized professional diploma certificate. The number of training hours for the diploma certificate was 360 hours, $30 \%$ of the hours was face to face, and it was achieved theoretically, on the other hand, $70 \%$ of the hours was achieved practically.

The participants in the program were engaged with the complexes in Table (1). 
Table 1. Complexes and topics of the E4F program

\begin{tabular}{|c|c|}
\hline Complex & Topics \\
\hline First complex & $\begin{array}{c}\text { Formulating educational philosophy, conducting action research, and employing reflection in } \\
\text { professional development. }\end{array}$ \\
\hline Second complex & $\begin{array}{c}\text { Learner-centered learning in terms of principles and conditions- Effective planning of the } \\
\text { learning process-Planning tools }\end{array}$ \\
\hline Third complex & Assessing learning: centered learning, project-based learning \\
\hline Fourth complex & Integration among the various subjects to plan and implement special projects. \\
\hline Fifth complex & $\begin{array}{l}\text { Designing and implementing assessment tools and building criteria and indicators for } \\
\text { assessment tasks. }\end{array}$ \\
\hline Sixth complex & $\begin{array}{c}\text { The implementation of various educational strategies: multiple intelligences, learning styles, and } \\
\text { teamwork. }\end{array}$ \\
\hline Seventh complex & $\begin{array}{l}\text { Designing student-friendly environment that foster positive relationships between students and } \\
\text { teachers }\end{array}$ \\
\hline Eight complex & $\begin{array}{c}\text { Continuous pursuit of professional development: building procedural plans and strengthening } \\
\text { professional ethics. }\end{array}$ \\
\hline
\end{tabular}

Table (2) includes examples of the strategies implemented by the participants in the program.

Table 2. Examples of strategies implemented by the participating teachers during the program

\begin{tabular}{|c|c|c|c|}
\hline Class & Grade & Topic & Strategy \\
\hline Physics & Tenth grade & Archimedes rule & procedural research \\
\hline Science and Life & Eighth grade & Elements of the periodic table & $\begin{array}{c}\text { Cooperative learning \& learning by } \\
\text { playing }\end{array}$ \\
\hline Chemistry & Tenth grade & Alkanes & Multiple intelligences \& learning styles \\
\hline Grammar & Tenth grade & $\begin{array}{l}\text { Examining the conditions of } \\
\text { constructing an action verb }\end{array}$ & $\begin{array}{l}\text { Explaining by using the mind map } \\
\text { strategy }\end{array}$ \\
\hline Reading & Ninth Grade & Sports and Health lesson & $\begin{array}{c}\text { Explanation of the listening triangle } \\
\text { strategy }\end{array}$ \\
\hline Writing & Ninth Grade & Summarization art & Collaborative learning \\
\hline Mathematics & Eighth grade & Trigonometric Ratios & Cognitive Journey \\
\hline Technology & Eleventh Grade & Computerized engineering drawing & Peer learning \\
\hline
\end{tabular}

\subsection{Data Collection Tools}

The data was collected using class observations and semi-structured interviews. The interview data was collected by asking various questions related to the research questions [13]. The average time of the interviews with the participants took nearly 45 minutes. Besides, six class observations were conducted for the six participating teachers. The interviews were recorded, and the class observations were filmed. Then, the interviews and class observations were transcribed, and the texts were given to those teachers to check them. Besides, we used thematic coding to code the data and demonstrate the themes.

\subsection{Data Analysis Tools}

According to Dacin et al. [14], Gioia approach came in line with our study for we were working on main and sub codes as a qualitative analysis process, where we took care of first and second order data. First order codes are closest to the data, and aggregated to develop second order codes. For instance, the first main theme was teaching competencies; it was divided into the following second order themes: teaching strategies, classroom management, using technology, assessment strategies, values and attitudes, and students' interaction. The second main theme was about challenges and external support. It was divided into the following second order themes: the challenge of the technical aspect and the challenge of using the new competencies in the classroom.

Dacin et al. [14] emphasize that we need to show snippets of data to illustrate the contents within a code. For example, to support the themes, we used some quotations. For example, we supported the theme of using technology by the quotation: "I learned how to cut a video and how to design an educational website; I learned all of those skills during the program.

\subsection{Validity and Reliability}

To ensure the validity and reliability of the study, the researchers discussed the themes and sub-themes before approving the final themes. To ensure reliability and validity of data analysis, each researcher worked alone, transcribed the interviews and observation, and coded them. Two researchers collected the data by conducting the interviews and class observations. Then, three 
researchers analyzed $5 \%$ the transcriptions of the interviews and observations. The inter-rater reliability between the coders was initially $71.42 \%$. After the three researchers discussed and negotiated the results of the coding, the inter-rater reliability among the coders was $85.71 \%$.

\section{Results}

The study aimed to study the effect of the program, E4F, on teachers' competencies for teaching in the classroom. The research results indicated that the $\mathrm{E} 4 \mathrm{~F}$ program had positive effects on the participants' classroom management, the teaching methods and strategies which the participating teachers used in the classroom, assessment strategies, values and attitudes, as well as on students' interaction. Below we elaborate the program effect on each one of the previous aspects.

\subsection{Classroom Management}

The E4F program had a positive effect on teachers' competencies in classroom management. The improvement in classroom management enabled more fruitful learning environment, better attraction of students' attention, more student' participation and autonomy, and better chances in teaching in line with the lesson plan. The English teacher stated that the program affected the learning environment positively. She said: "My $5^{\text {th }}$ and $6^{\text {th }}$ grades English students are completely attracted to the English Class."

\subsection{Teaching Strategies}

The teachers stated that the E4Fprogram positively affected their teaching competencies related to teaching strategies and practices inside the classroom. Through participating in the program, they adopted new teaching strategies as part of their teaching practices instead of the teaching methods they used to utilize in their teaching. They reported that they become able to apply to active learning strategies, taking account of the learning styles and multiple intelligences. They were also able to communicate and provide feedback to their students outside the classroom. The following quotations illustrate the teachers' adoption and activation of active learning strategies. The technology teacher said: "They asked us to apply active learning strategies inside the classroom, we implemented many sample classes, and we applied many strategies such as flipped learning strategy, SOLO strategy, dialogue and discussion strategy, and listening triangle strategy."

The teachers agreed that the program helped them discover students' learning styles and taking these styles into consideration while teaching. The Mathematics teacher said: "Knowing the learning styles helped me take into consideration individual differences among my students. Students can be visual, aural or physical. As part of my new teaching of mathematics, the students did many visual, aural and physical activities while learning"

The teachers agreed that the program helped them discover the multiple intelligences aspect and how to utilize these intelligencesin preparing activities for their students' learning. The teachers took advantage of the multiple intelligences through using new methods and strategies such as flipped classroom, project learning, cooperative learning, role play, SOLO strategy, Jigsaw, and technology- based journeys such as cognitive journeys that activate communication skills and providing feedback outside the school, were clear. The science teacher emphasized the positive improvement of utilizing multiple intelligences methods: "I had a group of students who had musical intelligence; thus, we created a song, and my students were singing. I noticed that they were muttering in the exam in order to know the answers."

Observations of the teachers' lessons revealed that many educational strategies were applied such as group working, learning styles, physical intelligence, learning by playing and visual learning styles like concept mapping. Working in groups appeared when the teacher distributed worksheet and helped them to work in groups. In addition, the physical learning styles appeared when the teacher asked the students to stand according to their numbers, and it also appeared when the teacher asked their students to act swimming and other activities. Besides, learning by playing appeared when the teacher asked 10 girls to participate in an educational game.

\subsection{Assessment Strategies}

The E4Fprogram affected the participating teachers' competencies related to assessment strategies, as the assessment of learning skills and weaknesses, formulating goals in different ways, employing various assessment tools, creating remedial action plans according to weakness, dealing with students' achievement, forming electronic tests, encouraging students by giving them extra marks, forming different kinds of questions and taking into consideration students' reflections on the class. Specifically, the program also encouraged the teachers to employ different assessment tools. The English teacher said:" We were trained how to form a rubric which is great for real assessment. " During the observation of English teacher's lessons, one student told the teacher: "I like the assessment methods you started to use in your class, they give us more assessment options."

\subsection{Using Technology}

The E4Fprogram affected positively the integration of technology in the classroom. The teachers started to use technological tools more regularly. These tools included LCDs, PowerPoint program, making videos, electronic 
tests, designing electronic websites, cards and electronic teaching aids. The mathematics teacher said:" I learned how to cut a video and how to design an educational website; I learned all of those skills during the program. " Another mathematics teacher said: "We learned many programs such as logarithm, painter and working on equations inside the classroom." In addition, according to the class observations, the Biology and Chemistry teacher presented the subject using interactive PowerPoint program, LCD, games and some videos. The observations showed that using technological tools made the students effectively interact with the given tasks.

\subsection{Students' Interaction}

The E4Fprogramshifted the process of teaching to be student- centered. The class observation showed that students' interactions with the given tasks increased. These interactions included answering questions, discussing ideas and raising new problems. For instance, the English Language teacher said: "The new teaching practices reduced students' distraction and boredom while it increased their participation and interaction." Moreover, a mathematics teacher said: "All of my students were raising their hands to answer the questions."

\subsection{Values and Attitudes}

The E4Fprogram affected teachers' attitudes and values positively, including their attitudes towards teaching strategies as encouraging cooperation among students. In addition, it positively affected the way in which teachers perceive their career. It also fostered the spirit of cooperation and competition among teachers who teach different subjects such as mathematics and technology. The technology teacher said:" We started to have the spirit of competence and to see value in this competence." The Biology and Chemistry teacher said:" The spirit of competence moved to my relations with my students. I now see myself as a role model for my students; my main aim in my life is to raise a generation that is skilled in problem solving."

However, many challenges emerged while implementing the program and the teachers could encounter them in different ways.

\subsection{Challenges and External Support}

When the teachers were asked about the challenges they encountered during the training and how they overcame these challenges, The Biology and Chemistry teacher said that the challenges were technical. The technical challenges were the lack of the required skills such as using LCD and smart board, or downloading the required videos and programs. Moreover, some students did not have computers or internet inside and outside the school.
In addition, time was another challenge; as the modern educational strategies and methods took, at the beginning, a lot to time to be implemented. Moreover, the students took a lot of time to get used to learn by using those methods and strategies. One mathematics teacher said:" I used to prepare seriously for the activities and tasks which I was going to implement, and my students took a lot of time to get used to leaning by those new methods." The Arabic teacher added: "The challenges were technical since I was senior teacher who did not know anything about technology."

When the teachers were asked about the ways they resort to in order to overcome the challenge, they stated the following. First, the school principal encouraged them by providing all the required technological tools and training. Moreover, the parents bought computers to their daughters, and made the internet network available for their home use. Also, the teachers supported and helped each other during the training. Besides, the trainer helped them a lot to overcome the challenges. A teacher stated:" When we were asked to record a class, the technology teacher helped by filming and creating a video. " Another teacher stated:" The principal brought LCD, posters, drawings and paintings."

\section{Discussion and Conclusions}

The present study intended to study the effect of E4Fprogram on teachers' competencies. The results showed that the training program developed teachers' competencies in different aspects including classroom management, teaching strategies, assessment strategies, using technology, students' interaction and values and attitudes. These results are in line with Desimone [6] who found that effective professional development updates teachers content knowledge, exposes them to new teaching strategies, sustains their teaching effectiveness and promotes their continuous growth. Desimone [6] emphasized professional development is a key strategy available to schools and school systems for improving teaching quality. The results demonstrated that the teachers were able to evaluate the process of teaching after involving in the training program. The E4Fprogram served the teachers in having knowledge of children's learning styles, how they address different individuals, how they evaluate teaching and how to manage a class. The previous knowledge is pointed at by researchers as needed for the teaching profession [3]. Moreover, the research showed that effective educating programs can help educators develop the different competencies needed for their teaching [7], including effective and different assessment methods as formal tests, quizzes, class assignments, student performances, projects, and standardized achievement tests to understand what students have learned. In addition, the effective educating 
program reported in the present research helped the participating teachers develop their students' self-assessment, as well as their students' awareness of their strengths and needs. Indeed, the previous two studies showed that improving teaching competencies required developing and activating assessment which fostered the process of effective and productive learning.

Moreover, the program developed the use of technology in teaching. Throughout the program, the participating teachers were using LCDs, PowerPoint program, making videos, electronic tests, designing electronic websites, cards and electronic teaching aids. This also meets the call of researchers to utilize the emerging technologies (e.g., [15]).

When the program developed teaching styles, strategies and methods, using technology, and assessment strategies, it had improved class management, students' interactions, values and attitudes. When the teachers became aware of the different teaching styles, strategies and methods, they could improve their students' interactions. This could have happened because, when the teachers used different methods, styles and strategies, they could attract their students' attention, increase their motivation, and address their different preferences and needs. Hence, using various methods, styles and strategies with assessment strategies could create active learning environment.

Furthermore, when the program improved the teaching styles, methods and strategies, which developed students' interactions, it could improve the classroom management effectively for the following reasons. First, when the teacher was aware of teaching methods and strategies, the teacher could manage the educational content usefully in various ways. Hence, the teacher and students became able to play their roles successfully. Second, when the teachers could play their roles effectively, it improved students" motivation and engagement. Therefore, it increased the students' interaction and participation. Third, when the students' interaction was improved, it developed classroom management since the students were fully engaged in different activities and the teacher was aware of managing every task done in the class. The previous results came in line with Irving and Martin (1982) who indicated that in order to establish a productive relationship with students; teachers need to have some qualities such as a high level of awareness, classroom management skills and an ability to make the learning environment qualified. The results answer the emphasis of Alter and Coggshall [3] who found that teachers should have knowledge of children's learning styles, how they address different individuals, how they evaluate teaching and how to manage a class. Indeed, knowing how to teach, how to motivate students, how to let them play their role and how to create an active learning environment, facilitates the process of managing the class easily.

The program encouraged the teachers to look at competence as positive. The requirement of the program encouraged the teachers to ask their colleagues for help and compete. In other words, it improved the values of cooperation and competition. Besides, when the teachers found they learned new things and their skills were developed, their competencies were improved. Consequently, their performance was developed. Thus, their attitudes towards teaching and themselves were improved since they found themselves successful and cooperative with others. The results show that effective educating programs can result in developing competencies needed for teachers (e.g., [7]) as effective classroom management, maximizing efficiency, maintaining discipline and morale, promoting teamwork, planning, communicating, focusing on results, evaluating progress, and making constant adjustments.

\subsection{Challenges and External Support}

According to the results, the study results indicated that the teachers encountered two main challenges: using technology in an appropriate way and introducing the new methods and strategies to students to enable them to engage in explorative learning. It was expected that the participating teachers face challenges and obstacles, while training and applying what they have learned, since they were exposed to new knowledge and tools. We argue that when teachers feel that they are challenged, this means they acquired new knowledge and ideas; in other words, they experienced and learned something new. Besides, it is expected for the teachers who did not use technology to face hardships since they were not accustomed to deal with it regularly. The previous explanation comes in line with Desimone [6] who emphasized that effective professional development programs expose teachers to new knowledge; otherwise, they will not be effective and productive.

In addition, the results of the current study found that the teachers resorted to other teachers, trainer or to their principal to overcome those challenges. It was expected from the trained teachers to ask their colleagues for help since they were being trained together, and it seemed according to the results of the study that they were cooperative with each other. Also, we think, it was logical for them to resort to the school principal since she was supportive as they said. That is, they were sure that they would receive help when they resorted to their colleagues and their principal, which indicates the role of cooperative learning environment in overcoming difficulties related to implementing new teaching competencies.

\subsection{Conclusions}

Shmelev [8] found that a competency is more than just knowledge and skills. Teachers need a wide range of competencies in order to face the complex challenges of today's world. Competent teachers are able to face the complex challenges they encounter. The present research 
proved that teachers' competencies could be developed through educating programs [16]. The current study found that the program developed teachers' competencies, which motivated the development of students' interaction, classroom management, using technology, and values and attitudes. Moreover, the results showed that the teachers faced challenges while utilizing the new competencies they acquired in the educating program; as introducing the new strategies and method to their students and using technology effectively. However, the results showed the teachers could overcome those challenges by cooperation and asking for help and support.

Indeed, when the program developed teaching styles, strategies and methods, using technology, and assessment strategies, it improved class management, students' interactions, and values and attitudes. Teachers' awareness of the different competencies needed for their profession was crucial. When the teachers were aware of different teaching styles, strategies and methods, they improved their practices. In addition, when the program improved the teaching styles, methods and strategies, and developed students' interactions, it improved the classroom management. Moreover, when the teachers were being trained in the frame of the program, it encouraged them to ask their colleagues for help and compete with each other. In other words, it improved the values of cooperation and competition. Besides, when the teachers found they learned new things and their skills were developed, their competencies were improved.

According to the results of the current study, we recommend that educational training programs should focus on active learning strategies as they have a positive impact on teacher practices. Moreover, educational training programs should focus on modern methods of classroom management, modern methods of students' assessment, and the use of technology. The previous methods are expected to affect positively students' learning, as they attract, and encourage students' attention and their interaction.

\section{REFERENCES}

[1] Boudersa, N. (2016). The importance of teachers' training and professional development programs in the algerian educational context: toward informed and effective teaching practices. ExpériencesPédagogiques journal, 1. https://exp-pedago.ens-oran.dz/experiences-pedagogiques/c ontributions_numero1/nacera-BOUDERSA.pdf

[2] Irving, O., \& Martin, J. (1982). Withitness: The confusing variable. American Educational Research Journal, 19(2), 313-319.

[3] Alter, J., \& Coggshall, J. G. (2009). Teaching as a clinical practice profession: Implications for teacher preparation and state policy. Washington, DC: National Professional Center for Teacher Quality.

[4] Richards, J. C. \& Farrel, T. S. C. (2005). Professional Development for Language Teachers: Strategies for Teacher Learning. Cambridge: Cambridge University Press.

[5] Wei, R. C., Darling-hammond, L., \& Adamson, F. (2010). Professional development in the United States: trends and challenges. Technical Report of the Stanford center for opportunity policy in education. Retrieved on 1/11/2019 from:

https://learningforward.org/docs/defaultsource/pdf/nsdcstud ytechnicalreport2010.pdf?sfvrsn=0

[6] Desimone, L., M. (2009). Improving impact studies of teachers' professional development: toward better conceptualizations and measures. Educational researcher, 38(3), 181-199.

[7] Nessipbayeva O (2012). The competencies of the modern teacher. Paper presented at the 10th Annual Meeting of the Bulgarian Comparative Education Society, Kyustendil, Bulgaria.

[8] Shmelev, A. G.(2002). Psychodiagnosis of personnel characteristics. Saint-Peterburg.

[9] Augskalne, I., Garjane,B.(2019). Formation of teachers' competences in further education. Proceedings of the International Scientific Conference, 5, 15-25.

[10] Pesti, C.(2019). The evolution of teacher education programs in different countries with a special focus on the role of practicum in developing teacher competences. Retrieved on 1/11/2019 from: https://ppk.elte.hu/file/csilla pesti_dissertation.pdf

[11] Peressini, D., Borko, H., Romagnano, L., Knuth, E., \& Willis, C.(2004). A conceptual framework for learning to teach secondary mathematics: A situative perspective. Educational Studies in Mathematics, 56(1), 67-96.

[12] Field, h. (1979). Competency Based Teacher Education (CBTE): A Review of the Literature, Journal of In-Service Education, 6(1), 39-42.

[13] Maxwell, J. A. (2013). Qualitative research design: An interactive approach(3rd ed.). Thousand Oaks, CA: Sage Publications.

[14] Dacin, M. T., Munir, K., \& Tracey, P. (2010). Formal dining at Cambridge colleges: Linking ritual performance and institutional maintenance. Academy of Management Journal, 53(6), 1393-1418.

[15] Baya'a, N., \& Daher, W. (2013). Mathematics teachers' readiness to integrate ICT in the classroom. International Journal of Emerging Technologies in Learning, 8(1), 46-52. doi:10.3991/ijet.v8i1.2386

[16] Baya'a, N., Daher, W., \& Anabousy, A. (2019). The development of in-service mathematics teachers' integration of ICT in a community of practice: Teaching-in-context theory. International JouOrnal of Emerging Technologies in Learning (iJET),14(1), 125-139. 